\title{
A Supply Chain Coordination Mechanism for Common Items Subject to Failure in the Electronics, Defense, and Medical Industries
}

\author{
Mikhail M. Sher*a \\ Telephone: +13152795498 \\ msher@keuka.edu \\ Seung-Lae Kim ${ }^{\mathrm{b}}$ \\ kims1@drexel.edu \\ Avijit Banerjee ${ }^{b}$ \\ banerjea@drexel.edu \\ Michael T. Paz \\ mtp58@cornell.edu
}

Last revised: May 2017

*Corresponding Author

${ }^{a}$ Division of Business and Management, Keuka College, 141 Central Avenue, Keuka Park, NY 14478

${ }^{\mathrm{b}}$ Decision Sciences and MIS Department, LeBow College of Business, Drexel University, 3141 Chestnut Street,, Philadelphia, PA 19104

${ }^{\mathrm{c}}$ S.C. Johnson College of Business, School of Hotel Administration, Cornell University, 435E Statler Hall, Ithaca, NY 14853 


\title{
A Supply Chain Coordination Mechanism for Common Items Subject to Failure in the Electronics, Defense, and Medical Industries
}

\begin{abstract}
$\underline{\text { Abstract }}$
Improved production processes, particularly miniaturization, have led to the development and use of non-reworkable items subject to failure in modern production environments. Coordinating supply chains for these items requires cooperation between suppliers and buyers in order to balance ordering/setup and holding costs among system partners. In this paper, we first determine optimal inventory policies for both the supplier and buyer. We then apply the bisection method to develop a mechanism which uses a common replenishment time to coordinate a supply chain consisting of a single supplier and $n$ buyers. By utilizing this optimization framework, we minimize total system-wide costs and derive the cost savings associated with our coordinated solution. Numerical examples are then provided for illustration.
\end{abstract}

JEL: C44.

Keywords: Inventory; bisection method; supply chain coordination; supply chain management. 


\section{Introduction}

Miniaturization and other improved production processes have created an increasingly important class of items not subject to rework (i.e. not cost effective to repair or technically irreparable) which are used across a wide range of industries. The electronics industry, for example, utilizes a variety of small transistors, circuits, and other small components which cannot be repaired upon failure due to their method of installation and/or relatively small size

(Dumbrowski, Schulze, \& Weckenborg 2011). Bullets, certain ballistic missile components, and other types of ordnance also exemplify a category of military supplies which are unable to be reworked upon failure (Rossi 1987). Additionally, certain sterile medical supplies (e.g. saline solution, sterile gauze, and other surgical supplies), whether due to feasibility or regulatory requirements, are similarly useless upon failure. These items share both the potential for probabilistic failure during storage and a general lack of feasible conditions for repair or rework upon failure. Medical supplies, for example, can experience failure during storage through loss of sterile conditions for a variety of reasons such as tampering, unexpected storage environment changes, or compromised packaging. Similarly, ordnance and electronic components can fail through exposure to water and extreme environmental conditions, rendering these items irreversibly damaged.

Our paper develops a supply chain coordination mechanism for items of this type for a supply chain consisting of a single supplier and $n$ buyers. In order to develop our coordination mechanism, we begin by considering optimal inventory policies for the buyers and seller under the economic order and production quantity (EOQ/EPQ) framework of Harris (1913) and Taft (1918). Having derived optimal inventory policies for individual members of the supply chain, we apply the bisection algorithm in order to coordinate the supply chain using a common 
replenishment time. System-wide costs are minimized through the use of our coordination mechanism, allowing us to propose potential methods through which cost savings can be shared with buyers in order to induce mutually-beneficial cooperation.

Supply chain coordination requires an understanding of the optimal inventory policies for both buyers and suppliers. Modeling optimal inventory policies for items that fail and are unusable after failure requires us to ease the basic assumption of perfect item quality within the EOQ/EPQ framework. Researchers have adapted this framework by relaxing its rigid assumptions to account for a variety of more practical inventory, addressing item quality problems and associated solutions in particular, within supply chains. Porteus (1986) and Lee and Rosenblatt (1987) each assume that defective items can be reworked or scrapped when developing their optimal production quantity models. Salameh and Jaber (2000) developed an inventory model for defective items which allows them to be kept in stock and sold at a discount rather than being reworked or scrapped. Others have extended this discounted disposal model in order to account for learning effects (Jaber, Goyal, \& Imran 2008) as well as process, repair, and maintenance deficiencies (Liao \& Sheu 2011). Khan, Jaber, Guiffrida, \& Zolfaghari (2011) provide a review of these and other extensions. In contrast to the discounted disposal or rework assumptions contained in these prior models, our model accounts for the case where item failure occurs such that items cannot be reworked, scrapped, or sold at a discount.

Optimal inventory policies inform efforts to coordinate supply chains by providing the preferred inventory levels for both buyers and suppliers. Banerjee (1986) derives a model through which a supply chain costs can be minimized in a mutually beneficial manner through the joint determination of lot sizing. Hill and Omar (2006) similarly rely on an integrated production-inventory model for a supply chain featuring a single supplier and a single buyer. Qi, 
Bard, and Yu (2004) consider a within a single-buyer, single-supplier production-inventory model with an additional demand disruption feature. We extend this general framework to include multiple buyers, rather than a single buyer, in order to support coordination of a more complex supply chain. Coordination is accomplished through the use of a common replenishment time. Viswanathan \& Piplani (2001) utilize a common replenishment time to coordinate a supply chain with a single supplier and multiple buyers. Sarmah, Acharya, and Goyal (2008) extend this model by considering issues of market power within the context of determining the common replenishment time. Our model extends the literature on common replenishment time by utilizing the bisection method to determine the appropriate common replenishment time (Joglekar 1988).

The remainder of this paper is organized as follows. The assumptions and notation used to describe our model are given in Section 2, while our EPQ model is developed and optimized in Section 3. Our supply chain coordination mechanism is developed in Section 4, with related numerical examples used to analyze the model in Section 5. Finally, Section 6 discusses methods for inducing cooperation among supply chain partners and provides our concluding remarks.

\section{Assumptions and Notation}

The following assumptions are used in the development of our model:

1. Demand rate, setup/order costs, and inventory holding costs are known and deterministic.

2. Production of items is continuous and at a constant rate during the production run.

3. Inventory is accumulated during the production period, with maximum inventory levels achieved at the end of the production period.

4. A $100 \%$ screening is performed when the lot is delivered to separate the defective items. 
5. Defective items are replaced at manufacturer's cost.

6. Lots are comprised of items with a failure rate with known probability density function.

7. Items which fail are not subject to rework.

The following notation is adopted:

$\begin{array}{ll}\text { Q } & \text { order quantity } \\ \mathrm{Q}^{*} & \text { optimal order quantity } \\ \mathrm{c} & \text { unit variable production cost } \\ \mathrm{K} & \text { setup cost per setup } \\ \mathrm{H} & \text { holding cost per unit per year } \\ \mathrm{S} & \text { selling price per unit } \\ \mathrm{T} & \text { cycle length } \\ \mathrm{D} & \text { yearly demand } \\ \mathrm{S}(\mathrm{t}) & \text { number of items in stock at time } \mathrm{t} \\ \mathrm{p} & \text { item failure rate } \\ \mathrm{G} & \text { yearly production rate, } \mathrm{G}>\mathrm{D}\end{array}$

\section{Mathematical Model and Optimization}

The basic EPQ model is derived from a total cost function which includes all production, setup, and holding costs (for the case of no failure) for an order as described in Equation (1):

$$
\text { Total Costs }=c D+\frac{D K}{Q}+\frac{H Q}{2}\left(1-\frac{D}{G}\right)
$$

Total cost minimization is achieved through differentiation, with the optimal production quantity calculated as the derivative of the total cost with respect to $Q$. Equation (2) provides the 
optimal order quantity obtained by deriving the first order optimality condition for Equation (1), hereafter identified as $Q^{*}$ :

$$
Q^{*}=\sqrt{\frac{2 D K}{H\left(1-\frac{D}{G}\right)}}
$$

Figure 1 provides a graphical representation of inventory flow under the EPQ model, with the areas of triangles (i) and (ii) indicating inventory levels at all times during the inventory cycle. Maximum inventory is calculated as a function of both production and demand, reflecting the fact that inventory is depleted during production. The area of the triangle (i) is calculated as $\frac{1}{2} Q\left(1-\frac{D}{G}\right) t_{1}$, and maximum inventory at time $\mathrm{t}_{1}$ is calculated as $\left(1-\frac{D}{G}\right) Q$. Calculating the area of triangle (ii) requires that we account for probabilistic failure of items following the end of the production period.

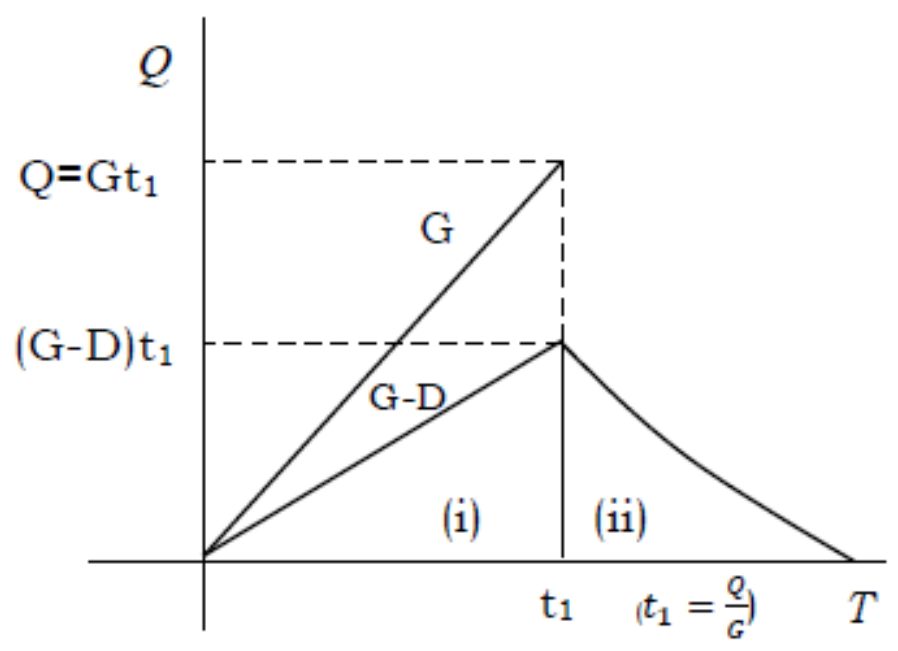

Figure 1: Inventory Level over Cycle Time - EPQ Model

We utilize the following exponential failure rate to simultaneously model inventory reduction associated with normal demand and probabilistic failure for our items:

$$
Q e^{-p t}-D t
$$

Thus, we use the following equation to calculate the area of the triangle (ii) in Figure 1: 


$$
\operatorname{Area}(i i)=\int_{t_{1}}^{T}\left[\left(1-\frac{D}{G}\right) Q e^{-p t}-D t\right] d t
$$

Average inventory is calculated by dividing the area under the total inventory curve by total cycle length $(T)$ :

$$
A v g . \operatorname{Inv} .=\frac{\frac{1}{2}\left(1-\frac{D}{G}\right) Q t_{1}+\int_{t_{1}}^{T}\left[\left(1-\frac{D}{G}\right) Q e^{-p t}-D t\right] d t}{T}
$$

We derive the order quantity $Q$ which minimizes the total cost function by setting the derivative $\frac{d T C Y}{d Q}$, where $T C Y$ is the total cost function including probabilistic failure, equal to zero and solving for $Q$. The total cost function is set equal to zero as follows:

$$
\frac{d T C Y}{d Q}=-\frac{D}{Q^{2}} K+\frac{d}{d Q}[A v g . I n v .] H=0
$$

In order to derive the optimal value for $Q$, we first evaluate Equation (5) for insertion into Equation (1).

$$
\begin{aligned}
\text { Avg.Inv. } & =\frac{\frac{1}{2}\left(1-\frac{D}{G}\right) Q t_{1}+\int_{t_{1}}^{T}\left[\left(1-\frac{D}{G}\right) Q e^{-p t}-D t\right] d t}{T} \\
& =\frac{1}{T}\left\{\frac{1}{2}\left(1-\frac{D}{G}\right) Q t_{1}+\left[\left(1-\frac{D}{G}\right) Q\left(-\frac{1}{p}\right) e^{-p t}-\frac{D t^{2}}{2}\right]_{t_{1}}^{T}\right\} \\
& =\frac{1}{T}\left\{\frac{1}{2}\left(1-\frac{D}{G}\right) Q t_{1}+\left(1-\frac{D}{G}\right) Q\left(-\frac{1}{p}\right) e^{-p T}-\frac{D T^{2}}{2}\right. \\
& =\frac{1}{T}\left\{\frac{1}{2}\left(1-\frac{D}{G}\right) Q t_{1}+\left[-\left(1-\frac{D}{G}\right) \frac{Q}{p} e^{-p T}-\frac{D T^{2}}{2}+\left(1-\frac{D}{G}\right) \frac{Q}{p} e^{-p t_{1}}+\frac{D t_{1}{ }^{2}}{2}\right]\right\} \\
& \left.=\frac{1}{T}\left\{\frac{1}{2}\left(1-\frac{1}{p}\right) e^{-p t_{1}}-\frac{D t_{1}{ }^{2}}{2}\right]\right\}
\end{aligned}
$$


where $t_{1}=\frac{Q}{G}$

To determine the optimal cycle time, we first calculate the cycle time for the period $t_{1}$ through $T$, or the storage period during which failure occurs. Next, we use that value to calculate total cycle time including both the production and storage periods. We then utilize the MacLaurin Series approximation framework to determine optimal cycle length.

Our cycle time is expressed as $t=T-t_{1}, t_{1}=\frac{Q}{G}$. We use $\frac{Q}{G}$ to identify $t_{1}$ as the total quantity produced that is equal to the production rate multiplied by the length of the production $\operatorname{period}\left(Q=G * t_{1}\right)$

$$
\begin{aligned}
& \left(1-\frac{D}{G}\right) Q e^{-p t}=D t \\
& D t \approx\left(1-\frac{D}{G}\right) Q\left(1-p t+\frac{1}{2} p^{2} t^{2}\right) \\
& \frac{1}{2}\left(1-\frac{D}{G}\right) Q p^{2} t^{2}-\left(1-\frac{D}{G}\right) Q p t-D t+\left(1-\frac{D}{G}\right) Q=0 \\
& t=\frac{\left(1-\frac{D}{G}\right) Q p+D-\sqrt{\left[\left(1-\frac{D}{G}\right) Q p+D\right]^{2}-4 \times \frac{1}{2}\left(1-\frac{D}{G}\right) Q p^{2}\left(1-\frac{D}{G}\right) Q}}{2 \times \frac{1}{2}\left(1-\frac{D}{G}\right) Q p^{2}}
\end{aligned}
$$

Simplifying expression (11), we obtain:

$$
t=\frac{\left(1-\frac{D}{G}\right) Q p+D-\sqrt{\left[\left(1-\frac{D}{G}\right) Q p+D\right]^{2}-2\left(1-\frac{D}{G}\right)^{2} Q^{2} p^{2}}}{\left(1-\frac{D}{G}\right) Q p^{2}}
$$

\section{Supply Chain Coordination Mechanism}

Having considered the manufacturer's problem through the development of an EPQ model for items experiencing probabilistic failure during storage, we next derive a coordination mechanism for a supply chain comprised of a single manufacturer and $n$ buyers for such items. Our supply chain coordination model utilizes information regarding the total cost of each of $n$ buyers within a supply chain. 
The inventory level of each buyer $i$ at time $t$ is described as $S(t)=Q e^{-p t}-D t$. The level of inventory continues to diminish over the inventory cycle period, reaching 0 at the end of the cycle time $T_{i}$. Figure 2 provides a graphical representation of inventory level $(Q)$ over cycle time (T) under both a standard EOQ model and the modified EOQ model incorporating probabilistic failure (Sher \& Kim 2015). Average inventory for each buyer, therefore, is expressed as:

$$
\begin{aligned}
\text { Average Inventory } & =\frac{1}{T_{i}} \int_{0}^{T_{i}}\left(Q_{i} e^{-p t}-D_{i} t\right) d t \\
& =\frac{1}{T_{i}}\left(-\frac{1}{p} D_{i} T_{i}-\frac{D_{i} T_{i}^{2}}{2}+\frac{Q_{i}}{p}\right)
\end{aligned}
$$

Inventory Level, $S(t)$

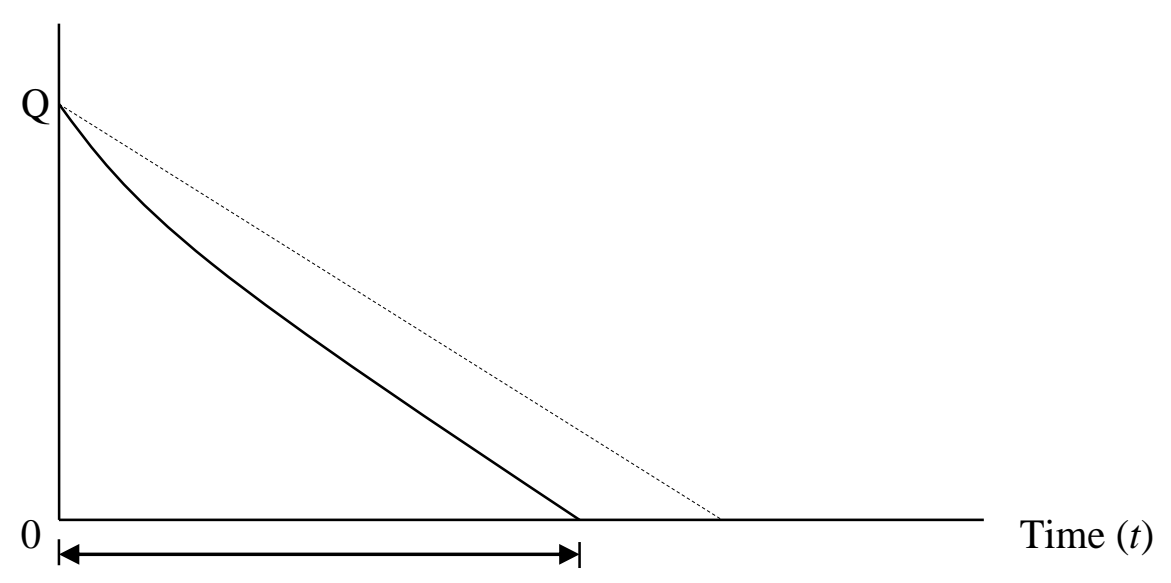

Cycle Time $(T)$

Figure 2: Inventory Level over Cycle Time - Standard EOQ vs. Modified EOQ model

Because $Q_{i} e^{-p T_{i}}=D_{i} T_{i}$, we can then determine the average inventory level for each buyer by substituting individual values for $Q_{i}=D_{i} T_{i} e^{p T_{i}}$ into equation (13).

$$
\text { Average Inventory }=\frac{1}{T_{i}}\left(-\frac{1}{p} D_{i} T_{i}-\frac{D_{i} T_{i}^{2}}{2}+\frac{D_{i} T_{i} e^{p T_{i}}}{p}\right)
$$


The total cost function for each of $i$ buyers (hereafter denoted as $T C B_{i}$ ) is comprised of holding and ordering costs.

$$
T C B_{i}=\frac{K_{b i}}{T_{i}}+\frac{H_{b i}}{T_{i}}\left(-\frac{1}{p} D_{i} T_{i}-\frac{D_{i} T_{i}^{2}}{2}+\frac{D_{i} T_{i} e^{p T_{i}}}{p}\right)
$$

Simplifying the expression above, we obtain:

$$
\begin{aligned}
T C B_{i} & =\frac{K_{b i}}{T_{i}}-\frac{H_{b i} D_{i} T_{i}}{p T_{i}}-\frac{H_{b i}}{T_{i}} \frac{D_{i} T_{i}^{2}}{2}+\frac{H_{b i}}{T_{i}} \frac{D_{i} T_{i} e^{p T_{i}}}{p} \\
& =\frac{K_{b i}}{T_{i}}-\frac{H_{b i} D_{i}}{p}-\frac{H_{b i} D_{i} T_{i}}{2}+\frac{H_{b i} D_{i} e^{p T_{i}}}{p}
\end{aligned}
$$

Taking the first derivative of $T C B_{i}$ with respect to $T_{i}$ and setting it equal to 0 , we obtain.

$$
-\frac{K_{b i}}{T_{i}^{2}}-\frac{H_{b i} D_{i}}{2}+H_{b i} D_{i} e^{p T_{i}}=0
$$

We then derive the optimal replenishment cycle time for buyer $i$.

$$
T_{i}=\sqrt{\frac{K_{b i}}{H_{b i} D_{i}\left(e^{\left.p T_{i}-\frac{1}{2}\right)}\right.}}
$$

Next, we apply the bisection algorithm to Equation (15) in order to calculate each individual buyer's optimal replenishment time based on their demand and cost parameters. Finally, we derive second-order conditions for $T C B_{i}$ in order to assess the convexity of our solution with respect to $T_{i}$ for all values of $T_{i}>0$.

$$
\frac{\partial^{2} T C B_{i}}{\partial T_{i}^{2}}=\frac{K_{b i}}{T_{i}^{3}}+H_{b i} D_{i} p e^{p T_{i}}>0
$$

This demonstrates that our optimal value for the total cost of buyer $i$ represents a minimum solution for buyer $i$ 's costs.

Using the average inventory factor framework obtained by Joglekar (1988), hereafter denoted as $\beta_{m}$, we obtain: 


$$
\beta_{m}=\left(Q_{K}-1\right)-\left(Q_{K}-2\right) \frac{D}{G}=Q_{K}\left(1-\frac{D}{G}\right)+\left(2 \frac{D}{G}-1\right)
$$

We adopt the following additional notation:

$A_{i} \quad$ Buyer i's sum of holding and ordering costs before cooperation

T Common order replenishment time

We now develop an optimal policy mechanism that will allow the manufacturer to coordinate a supply chain consisting of $n$ buyers in order to achieve a common replenishment time. We denote the manufacturer's production quantity for the coordinated case as $Q_{K}$. As manufacturers typically produce items in batches, we express $Q_{K}$ as a positive integer multiple of the manufacturer's lot size.

$$
\begin{gathered}
\operatorname{TCM}\left(Q_{K}, T\right)=\frac{K_{m}}{Q_{K} T}+\frac{C_{c}}{T}+\frac{1}{2} H_{m} D T \beta_{m}+\sum_{i=1}^{n}\left\{\left(\frac{K_{b i}}{T}-\frac{H_{b i} D_{i}}{p}-\frac{H_{b i} D_{i} T}{2}+\frac{H_{b i} D_{i} e^{p T}}{p}\right)-A_{i}\right\} \\
\frac{\partial T C M}{\partial T}=-\frac{K_{m}}{Q_{K} T^{2}}-\frac{C_{c}}{T^{2}}+\frac{1}{2} H_{m} D \beta_{m}+\sum_{i=1}^{n}\left(-\frac{K_{b i}}{T^{2}}-\frac{H_{b i} D_{i}}{2}+\frac{H_{b i} D_{i} p e^{p T}}{p}\right)
\end{gathered}
$$

Setting $\frac{\partial T C M}{\partial T}$ equal to 0 , we obtain the following expression:

$$
-\frac{K_{m}}{Q_{K} T^{2}}-\frac{C_{c}}{T^{2}}+\frac{1}{2} H_{m} D \beta_{m}-\frac{1}{T^{2}} \sum_{i=1}^{n} K_{b i}-\frac{1}{2} \sum_{i=1}^{n} H_{b i} D_{i}+\sum_{i=1}^{n} H_{b i} D_{i} e^{p T}=0
$$

Solving for $\mathrm{T}$ we obtain

$$
T=\sqrt{\frac{\frac{K_{m}}{Q_{K}}+C_{c}+\sum_{i=1}^{n} K_{b i}}{\frac{1}{2} H_{m} D \beta_{m}-\frac{1}{2} \sum_{i=1}^{n} H_{b i} D_{i}+\sum_{i=1}^{n} H_{b i} D_{i} e^{p T}}}
$$

For values of $p$ and $T$ ranging from $0<p<1$ and $0<T<1,1<e^{p T}<e$. We select these bounds of interest due to the unlikelihood that the common replenishment time will be above one year within most practical contexts. Most organizations engage in budget planning, including product and raw materials ordering, on an annual basis rather than over longer periods of time due to the difficulties involves in long-range forecasting. Even in the unusual case where an 
organization has replenishment times which extend over several years, it would be unrealistic to coordinate such purchasing activity with other buyers over such an extended interval. Bounding $T$ at one year, therefore, reflects the relative rarity of organizations adopting a multi-year replenishment schedule, especially in environments involving supply chain coordination.

Using the derived values for $T$, the practical ranges of $T$ and $p$ values expressed in terms of their relationship to $T$ are as follows:

$$
\sqrt{\frac{\frac{K_{m}}{Q_{K}}+C_{c}+\sum_{i=1}^{n} K_{b i}}{\frac{1}{2} H_{m} D \beta_{m}-\frac{1}{2} \sum_{i=1}^{n} H_{b i} D_{i}+e \sum_{i=1}^{n} H_{b i} D_{i}}}<T<\sqrt{\frac{\frac{K_{m}}{Q_{K}}+C_{c}+\sum_{i=1}^{n} K_{b i}}{\frac{1}{2} H_{m} D \beta_{m}-\frac{1}{2} \sum_{i=1}^{n} H_{b i} D_{i}+\sum_{i=1}^{n} H_{b i} D_{i}}}
$$

Note that we obtain the expression above by substituting $e$ instead of $e^{p T}$ on the left side of the interval and 1 instead of $e^{p T}$ on the right side of the interval. Combining like terms in the denominators above, we obtain the simplified interval:

$$
\sqrt{\frac{\frac{K_{m}}{Q_{K}}+C_{c}+\sum_{i=1}^{n} K_{b i}}{\frac{1}{2} H_{m} D \beta_{m}+\left(e-\frac{1}{2}\right) \sum_{i=1}^{n} H_{b i} D_{i}}}<T<\sqrt{\frac{\frac{K_{m}}{Q_{K}}+C_{c}+\sum_{i=1}^{n} K_{b i}}{\frac{1}{2} H_{m} D \beta_{m}+\frac{1}{2} \sum_{i=1}^{n} H_{b i} D_{i}}}
$$

Using these ranges, we can obtain values of $T$ using iterative procedures which utilize the bisection method. The detailed application of this bisection method algorithm is shown in Appendix A. This method allows us to narrow the interval and obtain an approximate value of $T$ based on the values of relevant problem parameters.

Taking the second derivative of Equation (18) with respect to $T$, while keeping $Q_{K}$ fixed, we obtain the following expression:

$$
\frac{\partial^{2} T C M\left(Q_{K}, T\right)}{\partial T^{2}}=\frac{2 K_{m}}{Q_{K} T^{3}}+\frac{2 C_{c}}{T^{3}}+\sum_{i=1}^{n}\left(\frac{2 K_{b i}}{T^{3}}\right)+\sum_{i=1}^{n} H_{b i} D_{i} p e^{p T}>0
$$

Similarly, we can demonstrate that the equation (18) is also convex with respect to $Q_{K}$ : 
We can now substitute this expression for $\beta_{m}$ into the equation (18):

$$
\begin{aligned}
& \operatorname{TCM}\left(Q_{K}, T\right)=\frac{K_{m}}{Q_{K} T}+\frac{C_{c}}{T}+\frac{1}{2} H_{m} D T\left[Q_{K}\left(1-\frac{D}{G}\right)+\left(2 \frac{D}{G}-1\right)\right] \\
& +\sum_{i=1}^{n}\left\{\left(\frac{K_{b i}}{T}-\frac{H_{b i} D_{i}}{p}-\frac{H_{b i} D_{i} T}{2}+\frac{H_{b i} D_{i} e^{p T}}{p}\right)-A_{i}\right\} \\
& \begin{aligned}
\frac{\partial T C M}{\partial Q_{K}}=-\frac{K_{m}}{Q_{K}^{2} T}+\frac{1}{2} H_{m} D T\left(1-\frac{D}{G}\right) \\
\frac{\partial^{2} T C M\left(Q_{K}, T\right)}{\partial Q_{K}^{2}}=\left(-\frac{K_{m}}{T}\right)(-2) Q_{K}^{-3}=\frac{2 K_{m}}{T Q_{K}^{3}}>0
\end{aligned}
\end{aligned}
$$

Thus, we determine that Equation (18) is convex with respect to both $\mathrm{T}$ and $Q_{K}$ for all values of $T>0$, thereby showing that our solution minimizes total manufacturer costs.

\section{Numerical Examples}

In this section, we provide numerical results for three cases with varying buyer demands, number of buyers, manufacturer's transportation costs and failure rates in order to illustrate the potential cost savings available under the coordinated solution as compared to the standard EPQ model. Each of these cases utilizes the following supplier production parameters:

$\begin{array}{lll}\mathrm{G} & 7000 \text { units } & \text { Manufacturer Production Rate (per year) } \\ \mathrm{K}_{\mathrm{m}} & \$ 250 & \text { Manufacturer Setup Cost (per setup) } \\ \mathrm{Hm} & \$ 2 & \text { Manufacturer Holding Cost (per unit per year) } \\ \mathrm{C}_{\mathrm{c}} & \$ 100 & \text { Manufacturer Transportation Cost (per delivery) } \\ \mathrm{p} & 0.25 & \text { Failure Rate }\end{array}$

In the first case (hereafter referred to as Case 1), we use the following demand and cost parameters for each of 5 buyers: 


$\begin{array}{lccc}\text { Buyer } & \begin{array}{c}\text { Demand }\left(\mathbf{D}_{\mathbf{i}}\right) \\ \text { (per year) }\end{array} & \begin{array}{l}\text { Ordering Cost }\left(\mathbf{K b}_{\mathbf{i}}\right) \\ \text { (per order) }\end{array} & \begin{array}{c}\text { Holding Cost }\left(\mathbf{H b}_{\mathbf{i}}\right) \\ \text { (per unit per year) }\end{array} \\ 1 & 300 & 20 & 3 \\ 2 & 550 & 15 & 3.3 \\ 3 & 350 & 6 & 3.6 \\ 4 & 200 & 10 & 3.6 \\ 5 & 700 & 18 & 2.5\end{array}$

We use these buyer demand and cost parameters to calculate common order replenishment times using the bisection method described in the previous section and Appendix A. Common order replenishment times ( $T$ ) for two, three, four, and five buyers are listed in Table 1.

\begin{tabular}{|c|c|c|}
\hline \# of Buyers & Buyers & $\boldsymbol{T}$ \\
\hline 1 & 1 & - \\
\hline 2 & $1 \& 2$ & 0.267 \\
\hline 3 & $1,2, \& 3$ & 0.247 \\
\hline 4 & $1,2,3, \& 4$ & 0.241 \\
\hline 5 & $1,2,3,4, \& 5$ & 0.227 \\
\hline
\end{tabular}

Table 1: Common Order Replenishment Times for Case 1

Having calculated the common order replenishment times, we next calculate total system costs (TC) with and without coordination and determine the level of cost savings achieved through the use of a common order replenishment time (TCS). We report these results in Table 2.

\begin{tabular}{|l|c|c|c|c|}
\hline & $\begin{array}{c}\text { TC (without } \\
\text { coordination) }\end{array}$ & $\begin{array}{c}\text { TC } \text { (with } \\
\text { coordination) }\end{array}$ & TCS $(\$)$ & TCS (\%) \\
\hline 2 buyers & $\$ 2,424.94$ & $\$ 1,587.93$ & $\$ 837.01$ & $34.52 \%$ \\
\hline 3 buyers & $\$ 3,709.81$ & $\$ 1,895.18$ & $\$ 1,814.63$ & $48.91 \%$ \\
\hline 4 buyers & $\$ 4,501.96$ & $\$ 2,083.16$ & $\$ 2,418.80$ & $53.73 \%$ \\
\hline 5 buyers & $\$ 5,671.33$ & $\$ 2,545.67$ & $\$ 3,125.66$ & $55.11 \%$ \\
\hline
\end{tabular}

Table 2: Total Cost and Total Cost Savings for Case 1 
As can be seen in Figure 3, the coordinated solution achieves total system cost savings for all cases with multiple buyers. Additionally, the percentage cost savings increase along with the number of buyers suggesting that the use of a common order replenishment time may be more beneficial for companies with larger numbers of buyers.

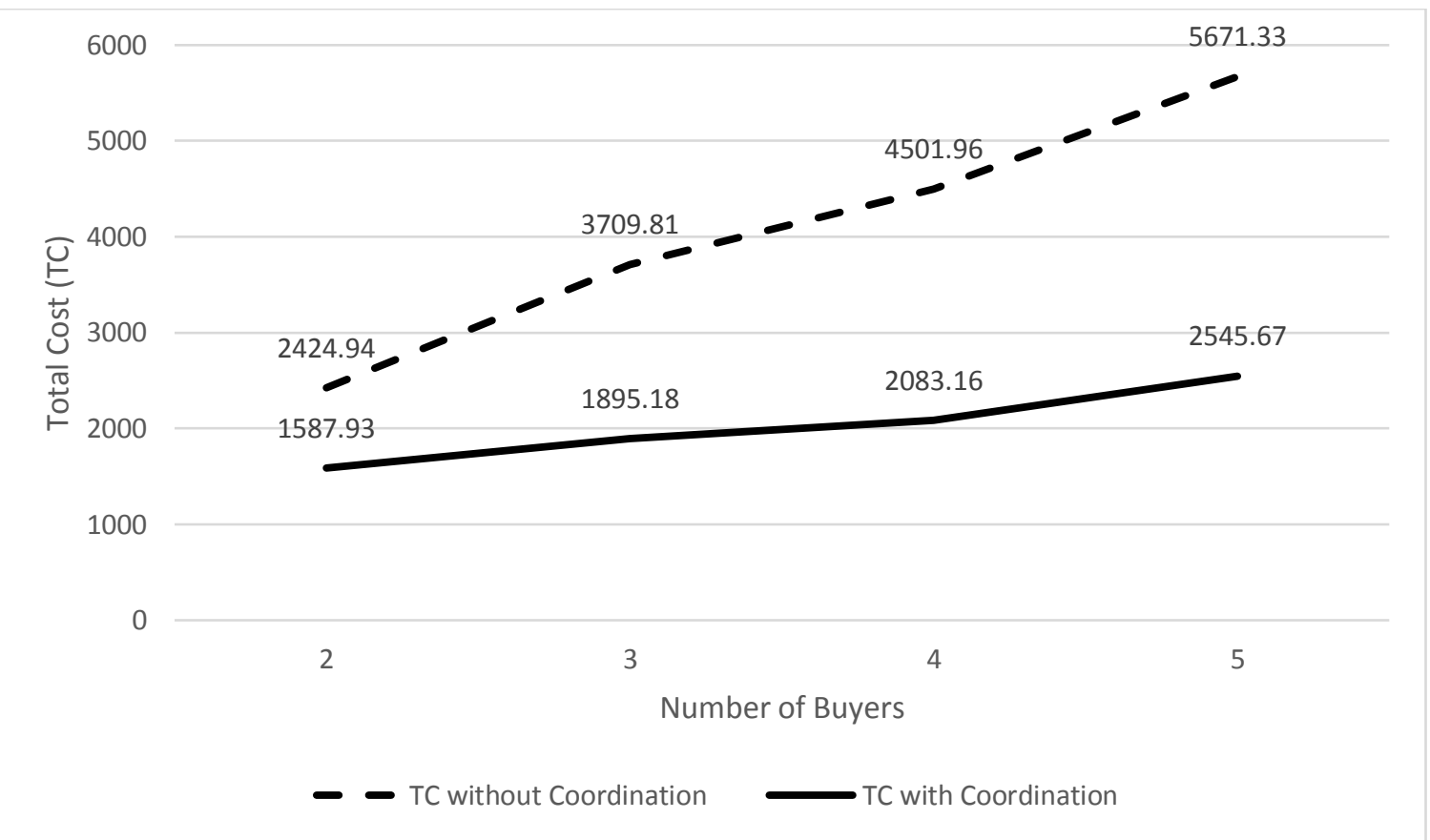

Figure 3: Graph of Total Costs with and without Coordination

\begin{tabular}{|c|c|c|}
\hline Buyer & $\begin{array}{c}\text { \# of deliveries without } \\
\text { coordination }\end{array}$ & $\begin{array}{c}\text { \# of deliveries with } \\
\text { coordination }\end{array}$ \\
\hline 1 & 4.7 & 4.4 \\
\hline 2 & 7.8 & 4.4 \\
\hline 3 & 10.2 & 4.4 \\
\hline 4 & 6.0 & 4.4 \\
\hline 5 & 7.0 & 4.4 \\
\hline
\end{tabular}

Table 3: Average Number of Deliveries (per year) for Five Buyers for Case 1

Table 3 reports the number of deliveries for each buyer with and without coordination. A portion of the cost savings achieved through coordination is related to transportation cost 
savings. As such, we consider a second case in which buyer demand is higher in order to demonstrate the sensitivity of our cost savings model to changes in buyer demand. We utilize the following buyer parameters which feature a doubling of annual demand:

$\begin{array}{lccc}\text { Buyer } & \begin{array}{c}\text { Demand }\left(\mathbf{D}_{\mathbf{i}}\right) \\ (\mathbf{p e r} \text { year) }\end{array} & \begin{array}{c}\text { Ordering Cost }\left(\mathbf{K} \mathbf{b}_{\mathbf{i}}\right) \\ (\text { per order) }\end{array} & \begin{array}{c}\text { Holding Cost }\left(\mathbf{H} \mathbf{b}_{\mathbf{i}}\right) \\ (\mathbf{p e r} \text { unit per year) }\end{array} \\ 1 & 600 & 20 & 3 \\ 2 & 1,100 & 15 & 3.3 \\ 3 & 700 & 6 & 3.6 \\ 4 & 400 & 10 & 3.6 \\ 5 & 1,400 & 18 & 2.5\end{array}$

Again, we use the bisection method and updated buyer demand and cost parameters to calculate common order replenishment times, which are listed in Table 4.

\begin{tabular}{|c|c|c|}
\hline \# of Buyers & Buyers & $\boldsymbol{T}$ \\
\hline 1 & 1 & - \\
\hline 2 & $1 \& 2$ & 0.234 \\
\hline 3 & $1,2, \& 3$ & 0.198 \\
\hline 4 & $1,2,3, \& 4$ & 0.186 \\
\hline 5 & $1,2,3,4, \& 5$ & 0.162 \\
\hline
\end{tabular}

Table 4: Common Order Replenishment Times for Case 2

We calculate total system costs with and without coordination and total cost savings under a common order replenishment time for scenarios ranging from 2 to 5 buyers and report these values in Table 5. Additionally, we calculate the number of deliveries per year for each buyer with and without coordination. As shown in Table 6, the number of deliveries increases by only $41 \%$ despite a doubling of demand. Total costs also increased by less than $50 \%$, demonstrating the economies of scale associated with utilizing a common order replenishment time. Our model continues to provide significant cost savings (over 50\%) under conditions of increased demand 
and order frequency, thereby supporting the applicability of our framework to high demand items which experience failure during storage and which are ordered in large quantities. The medical industry, in particular, makes use a wide variety of sterile medical supplies which can be damaged or otherwise fail during storage. Our model is directly applicable to this type of product.

\begin{tabular}{|l|c|c|c|c|}
\hline & $\begin{array}{c}\text { TC } \text { (without } \\
\text { coordination) }\end{array}$ & $\begin{array}{c}\text { TC } \text { (with } \\
\text { coordination) }\end{array}$ & TCS $(\$)$ & TCS (\%) \\
\hline 2 buyers & $\$ 3,429.90$ & $\$ 2,182.12$ & $\$ 1,247.78$ & $36.38 \%$ \\
\hline 3 buyers & $\$ 5,252.39$ & $\$ 2,645.29$ & $\$ 2,607.10$ & $49.64 \%$ \\
\hline 4 buyers & $\$ 6,373.29$ & $\$ 2,919.18$ & $\$ 3,454.11$ & $54.20 \%$ \\
\hline 5 buyers & $\$ 8,022.21$ & $\$ 3,582.17$ & $\$ 4,440.04$ & $55.35 \%$ \\
\hline
\end{tabular}

Table 5: Total Cost and Total Cost Savings for Case 2

\begin{tabular}{|c|c|c|}
\hline Buyer & $\begin{array}{c}\text { \# of deliveries without } \\
\text { coordination }\end{array}$ & $\begin{array}{c}\text { \# of deliveries with } \\
\text { coordination }\end{array}$ \\
\hline 1 & 6.7 & 6.2 \\
\hline 2 & 11.0 & 6.2 \\
\hline 3 & 14.5 & 6.2 \\
\hline 4 & 8.5 & 6.2 \\
\hline 5 & 9.9 & 6.2 \\
\hline
\end{tabular}

Table 6: Average Number of Deliveries (per year) for Five Buyers for Case 2

In the third case (hereafter referred to as Case 3), we consider the effects of increasing the manufacturer's transportation costs from $\$ 100$ to $\$ 200$ per delivery (with the other parameters from Case 1 remaining constant). While we observe a significant increase in common order replenishment times under the coordinated scenario, the total cost savings resulting from the coordination framework remain almost as large as in the original scenario. These results showcase the benefits of the model in situations with high delivery costs that frequently occur in 
both the defense and medical industries and can require secure or sterile delivery considerations, respectively.

\begin{tabular}{|c|c|c|}
\hline \# of Buyers & Buyers & $\boldsymbol{T}$ \\
\hline 1 & 1 & - \\
\hline 2 & $1 \& 2$ & 0.380 \\
\hline 3 & $1,2, \& 3$ & 0.322 \\
\hline 4 & $1,2,3, \& 4$ & 0.302 \\
\hline 5 & $1,2,3,4, \& 5$ & 0.261 \\
\hline
\end{tabular}

Table 7: Common Order Replenishment Times for Case 3

\begin{tabular}{|l|c|c|c|c|}
\hline & $\begin{array}{c}\text { TC } \text { (without } \\
\text { coordination) }\end{array}$ & $\begin{array}{c}\text { TC } \text { (with } \\
\text { coordination) }\end{array}$ & TCS $(\mathbf{\$})$ & $\begin{array}{c}\text { TCS } \\
(\%)\end{array}$ \\
\hline 2 buyers & $\$ 2,898.87$ & $\$ 1,836.81$ & $\$ 1,062.06$ & $36.64 \%$ \\
\hline 3 buyers & $\$ 4,183.74$ & $\$ 2,215.95$ & $\$ 1,967.79$ & $47.03 \%$ \\
\hline 4 buyers & $\$ 4,975.90$ & $\$ 2,431.68$ & $\$ 2,544.22$ & $51.13 \%$ \\
\hline 5 buyers & $\$ 6,200.70$ & $\$ 2,954.84$ & $\$ 3,245.86$ & $52.35 \%$ \\
\hline
\end{tabular}

Table 8: Total Cost and Total Cost Savings for Case 3

In addition to the cases outlined above, we consider simultaneous changes in item failure rate and manufacturer's transportation cost for a wide range of both parameters (with the other parameters from Case 1 remaining constant). We observe that a reduction of manufacturer's transportation cost from 100 to 50 results in $9.04 \%$ to $9.39 \%$ drop in total cost for a range of failure rates between 0.25 and 1 . Additionally, we observe that an increase in manufacturer's transportation cost from 100 to 200 results in $16.07 \%$ to $16.86 \%$ increase in total cost for the same range of failure rate values.

The results of the numerical examples presented in this section demonstrate the dramatic reductions in total supply chain costs which can be achieved through our coordinated solution for a wide range of parameter values, further validating the practical contributions of our model. 


\section{Discussion of Coordination Mechanisms and Summary}

Both supplier's and buyer's optimal inventory policies must be considered in developing mechanisms for inducing mutually beneficial cooperation within a supply chain (Arshinder \& Deshmukh 2008). Zimmer (2002) describes the problem of supply chain coordination as one of minimizing total system costs subject to the cost functions of both suppliers and buyers. Manufacturers tend to prefer larger order quantities and longer inventory cycles due to their relatively capital intense production processes. Adopting such policies allows manufacturers to maximize operational efficiency while minimizing production and transportation costs. By contrast, buyers prefer smaller, more frequent orders in order to maximize inventory flexibility and manage fluctuations in demand. Demand-driven, flexible inventory policies allow buyers to avoid stockouts and overstocks which erode profitability. Given these noteworthy differences in preferred inventory policies between suppliers and buyers, achieving the available cost savings associated with supply chain coordination requires cooperation among supply chain partners. Adoption of the common replenishment time proposed by our model generates significant cost savings which then provide the basis for supplier concessions designed to induce mutually beneficial cooperation ( $\mathrm{Li}$ and Wang 2007).

Sarmah et al. (2008) highlights the importance of generating cost savings through supply chain coordination efforts in order to provide a basis for negotiating a mutually beneficial common replenishment time. Suppliers can adopt a number of cost savings distribution policies in order to determine the overall proportion of cost savings which should be shared with buyers and the distribution of such savings among individual buyers. Assuming, therefore, that suppliers retain $\alpha \%$ of the costs savings achieved through coordination, the remaining (100- $\alpha) \%$, of such savings can be distributed to buyers using a variety of decision rules. For example, suppliers 
could share the unretained proportion of cost savings equally to each of $i$ buyers. Alternatively, cost savings could be distributed to buyers on the basis of their relative market share or cost concessions.

Having determined the proportion of cost savings to be conceded to buyers, the supplier must then decide upon the form such concessions will take. Cooperation between suppliers and buyers can be induced by the supplier providing both a quantity discount and a constant reorder interval discount (Taylor 2002; Cachon 2004; Li \& Liu 2006). Cooperation can also be sustained through bargaining over lot sizing and delivery intervals rather than adopting one or the other's preferred inventory policies outright (Cheung and Lee 2002). To the extent that deviating from the supplier's optimal inventory policies erodes system-wide cost savings, however, suppliers will have fewer cost savings available from which to provide concessions. Prior literature has identified expense sharing as a form of supplier concession, including cooperative advertising (Huang, Li, and Mahajan 2002), buybacks and operating subsidies (Cho and Gerchak 2005; Moses and Seshadri 2000), and risk sharing contracts (Chen, Chen, and Chen 2006) where suppliers and buyers share the risk of demand fluctuations between periods. In each of these cases, supply chain coordination and negotiation over supplier concessions may take place between arms-length parties (Fiestras-Janeiro, Garcia-Jurado, Meca, and Mosquera 2011) or, instead, may involve a third-party who aids in supply chain coordination (Masten and Kim 2015).

In this paper, we develop an EPQ model for items which experience probabilistic failure during storage and which are not subject to rework or disposal via lot discounting. We also develop an optimal policy mechanism for use in conjunction with the developed EPQ model which supports the coordination of a supply chain consisting of $n$ buyers through a common 
replenishment time. Through this optimization framework, we minimize total system-wide costs and derive the cost savings associated with our coordinated solution. These cost savings, as discussed earlier in this section, can be used to induce mutually beneficial cooperation between suppliers and buyers. We contribute to the EPQ literature by considering an important class of items which are widely used in the medical supply and electronics industries and modeling optimal supplier inventory policies for such items. 


\section{Acknowledgments}

The authors would like to thank Erik Benrud, Bruce McCullough, and Thomas McWilliams for their helpful comments and valuable feedback on this paper. 


\section{References}

Arshinder, A.K., \& Deshmukh, S.G. (2008). Supply chain coordination: Perspectives, empirical studies and research directions. International Journal of Production Economics, 115(2), 316-335.

Banerjee, A. (1986). A joint economic-lot-size model for purchaser and vendor. Decision Sciences, 17(3), 292-311.

Cachon, G.P. (2004). The allocation of inventory risk in a supply chain: Push, pull, and advancepurchase discount contracts. Management Science, 50(2), 222-238.

Chen, H., Chen, J., \& Chen, Y. (2006). A coordination mechanism for a supply chain with demand information updating. International Journal of Production Economics, 103(1), $347-361$

Cheung, K.L., \& Lee, H.L. (2002). The inventory benefit of shipment coordination and stock rebalancing in a supply chain. Management Science, 48(2), 300-306.

Cho, R.K., \& Gerchak, Y. (2005). Supply chain coordination with downstream operating costs: Coordination and investment to improve downstream operating efficiency. European Journal of Operational Research, 162(3), 762-772.

Dumbrowski, U., Schulze, S., \& Weckenborg, S. (2011). Evaluation of post-series supply strategies in regard of sustainability. In G. Seliger, M.M.K. Khraisheh, \& I.S. Jawahir (Eds.), Advances in Sustainable Manufacturing (pp. 337-341). New York, NY: Springer Science \& Business Media.

Fiestras-Janeiro, M.G., Garcia-Jurado, I., Meca, A., \& Mosquera, M.A. (2011). Cooperative game theory and inventory management. European Journal of Operational Research, $210(3), 459-466$. 
Harris, F.W. (1913). How many parts to make at once. Factory, the Magazine of Management, 10(2), $135-136 \& 152$.

Hill, R.M., \& Omar, M. (2006). Another look at the single-vendor, single-buyer integrated production-inventory problem. International Journal of Production Research, 44(4), 791800.

Huang, Z., Li, S.X., \& Mahajan, V. (2002). An analysis of manufacturer-retailer supply chain coordination in cooperative advertising. Decision Sciences, 33(3), 469-494.

Jaber, M.Y., Goyal, S.K., \& Imran, M. (2008). Economic production quantity model for items with imperfect quality subject to learning effects. International Journal of Production Economics, 115(1), 143-150.

Joglekar, P.N. (1988). A quantity discount pricing model to increase vendor profits. Management Science, 34(11), 1391-1398.

Khan, M., Jaber, M.Y., Guiffrida, A.L., \& Zolfaghari, S. (2011). A review of the extensions of a modified EOQ model for imperfect quality items. International Journal of Production Economics, 132(1), 1-12.

Lee, H.L., \& Rosenblatt, M.J. (1987). Simultaneous determination of production cycle and inspection schedules in a production system. Management Science, 33(9), 1125-1136.

Li, J., \& Liu, L. (2006). Supply chain coordination with quantity discounts. International Journal of Production Economics, 101(1), 89-98.

Li, X., \& Wang, Q. (2007). Coordination mechanisms of supply chain systems. European Journal of Operational Research, 179(1), 1-16. 
Liao, G.L., \& Sheu, S.H. (2011). Economic production quantity model for randomly failing production process with minimal repair and imperfect maintenance. International Journal of Production Economics, 130(1), 118-124.

Masten, K.A., \& Kim, S.L. (2015). So many mechanisms, so little action: The case for 3rd party supply chain coordination. International Journal of Production Economics, 168(1), 1320.

Moses, M., \& Seshadri, S. (2000). Policy mechanisms for supply chain coordination. IIE Transactions, 32(3), 245-262.

Porteus, E.L. (1986). Optimal lot sizing, process quality improvement and setup cost reduction. Operations Research, 34(1), 137-144.

Qi, X., Bard, J. F., \& Yu, G. (2004). Supply chain coordination with demand disruptions. Omega, 32(4), 301-312.

Rossi, M.J. (1987). Nonoperating Reliability Databook. Griffiss, NY: Reliability Analysis Center.

Salameh, M.K., \& Jaber, M.Y. (2000). Economic production quantity model for items with imperfect quality. International Journal of Production Economics, 64(1-3), 59-64.

Sarmah, S.P., Acharya, D., \& Goyal, S.K. (2008). Coordination of a single-manufacturer/multibuyer supply chain with credit option. International Journal of Production Economics, 111(2), 676-685.

Sher, M., \& Kim, S.L. (2015). An economic order quantity model for items experiencing failure in storage. International Journal of Operational Research, 22(4), 405-422.

Taft, E.W. (1918). The most economical production lot. The Iron Age, 101(May 30), 1410-1412. 
Taylor, T.A. (2002). Supply chain coordination under channel rebates with sales effort effects. Management Science, 48(8), 992-1007.

Viswanathan, S., \& Piplani, R. (2001). Coordinating supply chain inventories through common replenishment epochs. European Journal of Operational Research, 129(2), 277-286.

Zimmer, K. (2002). Supply chain coordination with uncertain just-in-time delivery. International Journal of Production Economics, 77(1), 1-15. 


\section{Appendix A: Application of the Bisection Method}

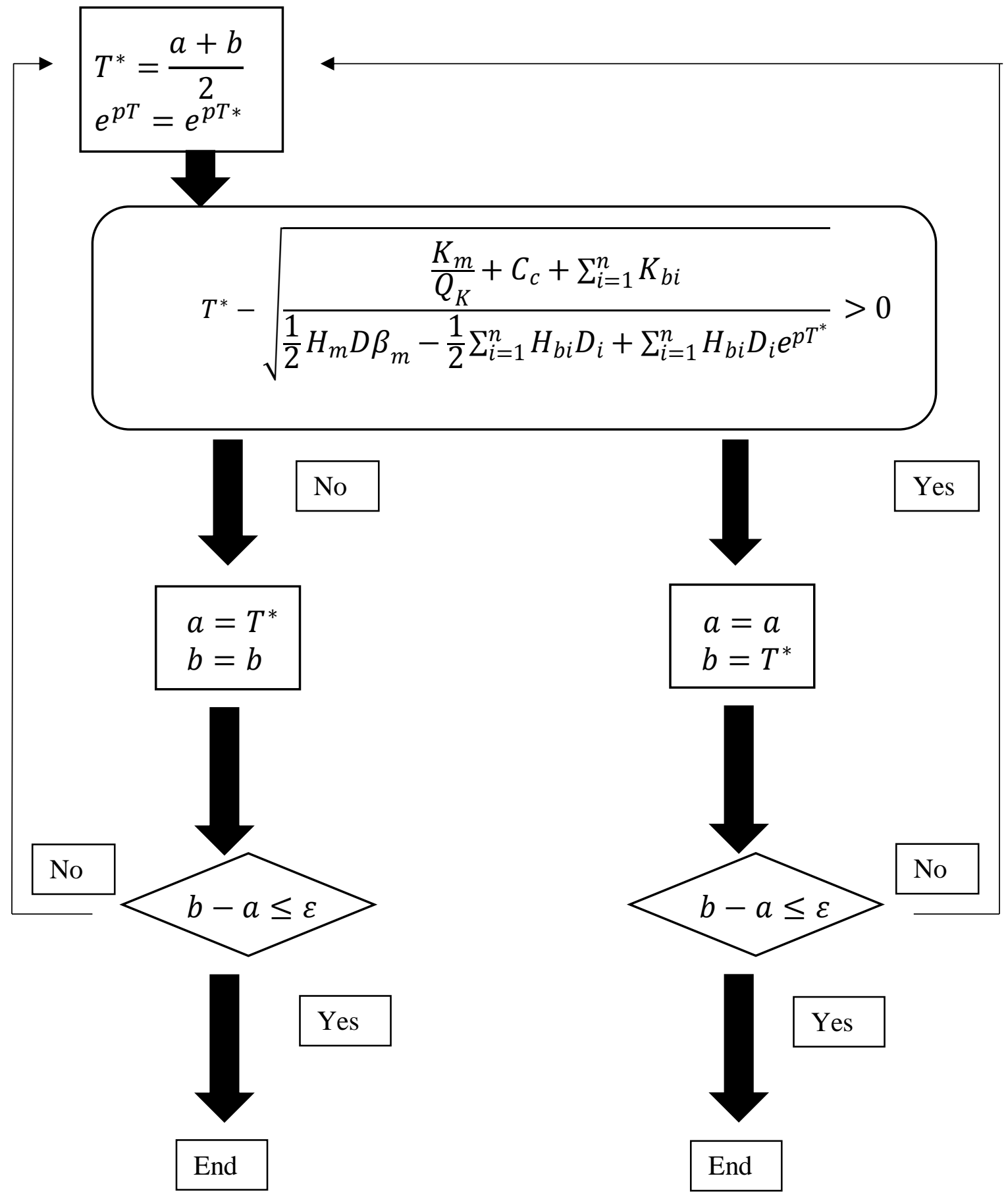

When desired precision level is reached 